\title{
The Role of Armadillos in the Movement of Archaeological Materials: An Experimental Approach
}

\author{
Astolfo G. Mello Araujo ${ }^{1}$ and José Carlos Marcelino ${ }^{2}$ \\ ${ }^{1}$ Laboratório de Estudos Evolutivos Humanos, Instituto de Biociências da \\ Universidade de São Paulo, SP CEP 05508-900, Brazil \\ ${ }^{2}$ Departamento do Patrimônio Histórico, Município de São Paulo, Praça \\ Coronel Fernando Prestes 152, SP CEP 01124-060, Brazil
}

\begin{abstract}
Armadillos are medium-sized animals whose burrowing behavior can be significant in archaeological settings ranging from South America to the central United States. Although archaeologists are well aware that these animals can move archaeological materials across stratigraphic layers, few data are available about the magnitude of mixing, number of burrows per individual, dimension of burrows, and their impact on archaeological sites. This paper addresses the problem from an experimental perspective. Specifically, we monitored the action of the yellow armadillo (Euphractus sexcintus) in translocating cultural materials. Our results suggest that: (1) the vertical movement of artifacts has no preferential direction; (2) cultural horizons at least $20 \mathrm{~cm}$ apart can be mixed; (3) the animal's activity leaves some distinct traces that can be recognized during an excavation; and (4) there is no significant correlation between size, shape, or weight of artifacts and amount of displacement. (C) 2003 Wiley Periodicals, Inc.
\end{abstract}

\section{INTRODUCTION}

The position of artifacts in soils and stratigraphic sequences plays a major role in the interpretation of archaeological deposits. Every definition of archaeological context takes into account the spatial relationship of individual specimens, whether among themselves or between them and the strata in which they are found, both horizontally and vertically.

This paper focuses on the issue of vertical movement of artifacts. There is a tendency in archaeology to take for granted that artifacts at the same level or in the same stratum are contemporaneous. However, research on the topic by many authors has shown that more often than expected, archaeological materials have the tendency of not staying where they were deposited (e.g., Bordes, 1972; Cahen and Moeyersons, 1977; Siiriäinen, 1977; Moeyersons, 1978; Rolfsen, 1980; Villa, 1982a, 1982b). Among the many variables responsible for displacement of artifacts is the action of burrowing animals such as ants, termites, earthworms, and rodents (Stein, 1983; Bocek, 1986; Johnson, 1990, 1993, 2002; Pierce, 1992; Araujo, 1995; Balek, 2002; Van Nest, 2002). There is, however, one animal that despite its regional 
ubiquity and notable burrowing behavior has received little attention in the archaeological literature: the armadillo.

Armadillos, because of their widespread distribution and strong burrowing activity, should be of interest to archaeologists. These mammals belong to eight genera and 20 species, all limited to the New World. Their range, depending on the species, extends from southern Brazil, Uruguay, and northern Argentina, to Mexico and the southeastern United States (Emmons and Feer, 1990). At least one species, the nine-banded armadillo (Dasypus novemcinctus), is undergoing a northward territorial expansion and can be found as far north as Missouri in the United States.

Our field observations in Brazil indicate that armadillos have great potential for disturbing cultural deposits. For instance, flakes and ceramic sherds are often found scattered around the entrance of armadillo burrows at archaeological sites. In some places, the density of contemporaneous burrows can be as high as 0.3 per $\mathrm{m}^{2}$ (Araujo, 1995), and archaeologists sometimes use armadillo burrows and the adjacent mounds as indicators of cultural materials that lie below. Although it seems clear that armadillos can move archaeological materials upward, previous studies have not considered whether they also move artifacts downward. Also, the magnitude of site disturbance by armadillos was unknown. The research questions addressed in this paper are as follows:

1. Are armadillos responsible for substantial vertical displacement of archaeological materials? If so, is there preferential direction of movement (e.g., more artifacts going up than down)?

2. Can they mix different layers of the same deposit? If so, what is the magnitude and nature of mixing?

3. Do the displaced artifacts show any spatial pattern, either vertically or horizontally?

4. Do the displaced artifacts present any modal value or threshold for weight, size, or shape?

5. Is it possible to recognize the action of armadillos from the way the displaced pieces are arranged?

\section{ARMADILLO ECOLOGY}

The first step in answering the questions listed above is to understand armadillo ecology and behavior. Unfortunately, literature on the topic is scarce. Few data are available about burrow extent, depth, number of chambers, number of entrances, period of occupation, and the intensity of burrowing activity among armadillos (some exceptions are Taber, 1945; Talmage and Buchanan, 1954; Carter and Encarnação, 1983). This precludes obtaining good estimates of soil modification and bioturbation caused by these animals, in contrast to assessments about well-studied animals such as the pocket gopher, Thomomys bottae (Erlandson, 1984; Bocek, 1986, 1992; Johnson, 1989; Pierce, 1992).

The most studied armadillo species is the nine-banded armadillo, Dasypus novemcinctus, a wide ranging species, and the only one found in North America. Its 
behavior gives some clues about its possible impact in archaeological settings. These animals select the same places as humans to reside: well-drained soils, river banks, and preferably out of the reach of seasonal inundation. When the landscape is flat, they will choose knolls or mounds to make their nests (Taber, 1945). Talmage and Buchanan (1954) noted that the easier the soil is to dig, the more elaborate and complex will be the burrows, and the greater their density. While $D$. novemcinctus reportedly have one or more home dens with many entrances, other species such as Euphractus sexcintus (yellow armadillo) and Priodontes maximus (giant armadillo) generally dig only one entrance and do not occupy a single burrow for extended periods (Carter and Encarnação, 1983). The width of the burrow is obviously related to the size of the animal. Priodontes maximus, for example, can dig burrows up to $45 \mathrm{~cm}$ wide. Measurements of burrow length are available only for D. novemcinctus. According to Taber (1945:217), burrows vary from 60 to 450 $\mathrm{cm}$ (2 to 15 feet) in length, and from a few decimeters to $120 \mathrm{~cm}$ deep.

Armadillos generally feed on insects such as ants and termites, although it is not uncommon for them to eat other small animals, carrion, and sometimes plants. Given the enormous potential for bioturbation already acknowledged for ants and termites, it is probably necessary to add armadillos to the equation. Another interesting point is that some areas of southeastern Brazil, armadillos are called "gravedigger armadillos" because of their habit of digging on cemetery graves (e.g., Baldus, 1937:48). In sum, armadillos play an important role in site formation processes. They can be found in a great variety of environments such as grasslands, forests, and semiarid settings, and they are restricted only by extremely cold temperatures or places with extended cold periods.

\section{THE EXPERIMENTAL SETTING}

In order to gain a better understanding of how armadillos affect archaeological deposits, we designed and conducted an experiment. The experiment was carried out at the São Paulo Zoo, Brazil, inside an elliptical concrete enclosure measuring $5.9 \mathrm{~m} \times 4.25 \mathrm{~m}$, with an approximate area of $16 \mathrm{~m}^{2}$. The enclosure had a straw roof and was partially open on the sides, with outer walls not exceeding $1.70 \mathrm{~m}$ in height. Two small inner walls (70 $\mathrm{cm}$ and $50 \mathrm{~cm}$ high) crossed the enclosure, dividing it into three areas (Figure 1). Under natural conditions, armadillos may burrow over a larger area, and the enclosure may have concentrated their burrowing activity. However, these factors do not negate our results because we are interested in the cumulative effects of burrowing.

The objective of the experiment was to simulate an archaeological deposit in a controlled manner. Flaked rock and ceramic sherds were stacked in horizontal layers at regular vertical spacing, and an armadillo was released into the enclosure to observe how its behavior modified the position of the experimental pieces.

We created a 60 -cm-thick stratified deposit with four horizontal artifact layers. All pieces placed in the same layer were spray-painted with the same color. The bottom layer, with all the pieces painted red, was placed directly on the concrete 


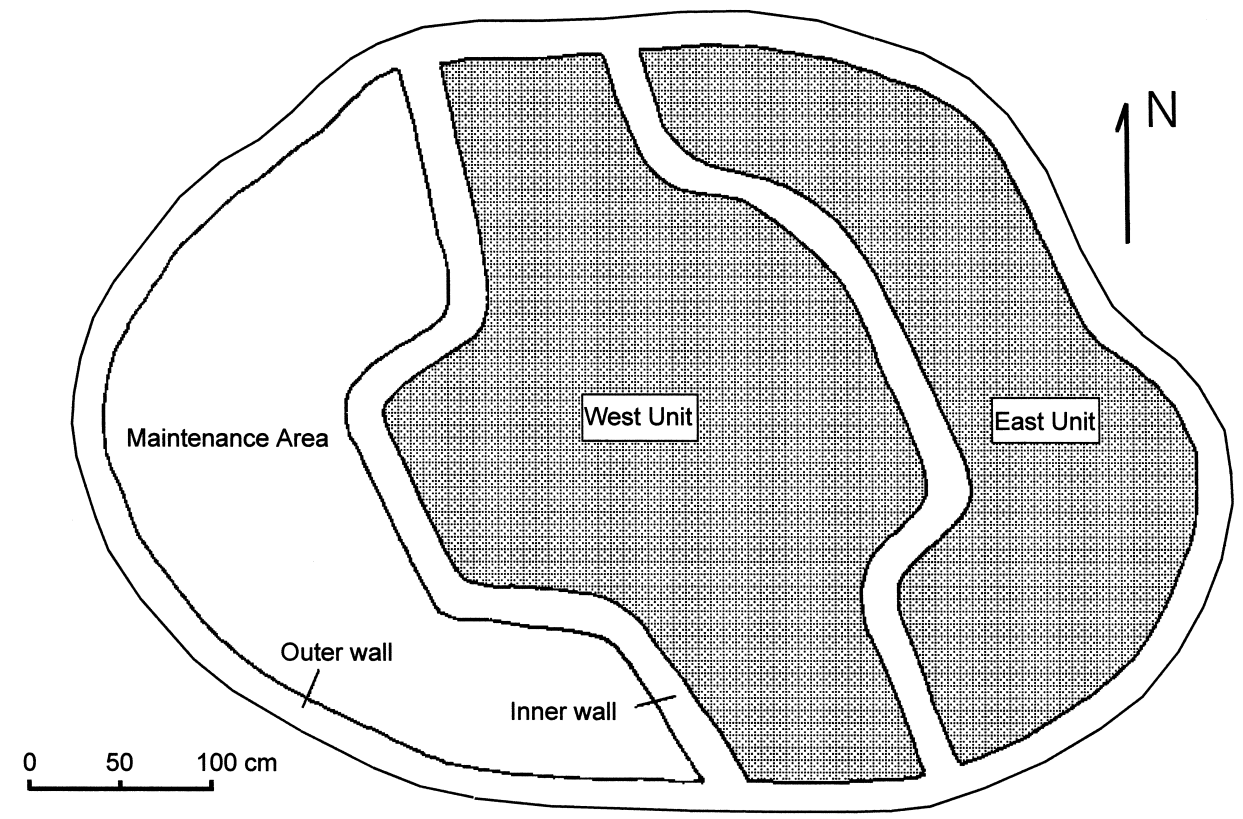

Figure 1. Plan view of the study area enclosure showing the filled area (shaded) and inner walls.

floor and covered with a 20-cm-thick sediment layer; the surface of the sediment was carefully leveled with the aid of an automatic level, and a second layer, with green artifacts, was deposited on this surface. The procedure was repeated, and a blue layer was placed $20 \mathrm{~cm}$ above the green layer and $20 \mathrm{~cm}$ below the surface. Finally, a layer of white and yellow ceramics was placed on the surface (Figure 2). The pieces were placed at regular intervals, with the distance between their centers never exceeding $15 \mathrm{~cm}$. We used two of the three areas inside the enclosure, designated East and West Units. In the East Unit, all four layers were composed of ceramics, whereas in the West Unit the lower three layers were all lithic, and the surface layer was all ceramic.

Because of our focus on the interaction between armadillos, deposits, and artifacts, we chose to control some parameters that actually are not constant in nature. For example, the experimental site was not subject to rainfall, so that there was no great fluctuation in sediment moisture and compaction, and there was no deposition or erosion. Also, the armadillo was alone, with its activity constrained by the walls, but not by the presence of other armadillos. Furthermore, there were no other living organisms large enough to affect the vertical position of the pieces, such as burrowing animals, and people were not allowed to tread on the experimental setting. These experimental conditions were aimed at isolating the burrowing effects of a single-species agent of turbation, the yellow armadillo, Euphractus sexcintus, and to gather data about its action without interference from other variables. 


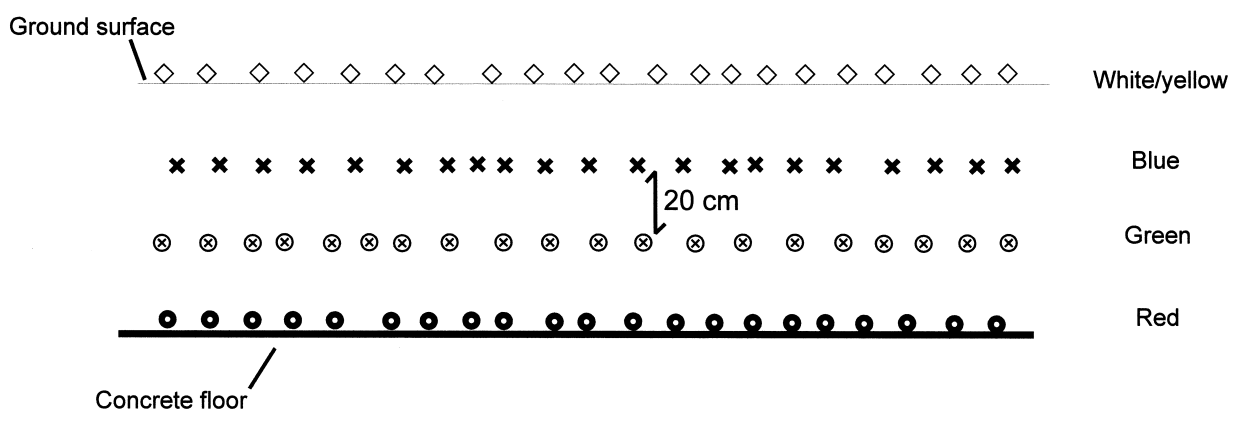

Figure 2. Schematic profile of the enclosure showing the original position of the four layers.

\section{PHYSICAL PROPERTIES OF THE MATERIALS}

The materials used in the experiment were flaked stone and ceramic sherds. The stone was silicified sandstone, a raw material commonly used by prehistoric populations in southeastearn Brazil (Araujo, 1992). Its composition basically consists of quartz grains coated and bound with siliceous cement $\left(\mathrm{SiO}_{2}\right)$ and minor impurities ( $\mathrm{Fe}$ ), thus presenting about the same specific gravity as any other siliceous rock. The original experimental design included observations on edge damage and pseudo-retouch on flakes, since armadillo claw marks were observed on archaeological materials by one of the authors. However, after conversations with the chief veterinarian of the Zoo, we concluded that a high concentration of razor-sharp edges would probably hurt the animal. In spite of the osseous carapace, armadillos have very sensitive skins on their abdomens, and in nature it is unlikely that any armadillo would find such a formidable density of sharp stones. Therefore, we ground the edges of every single flake using an electric emery to ensure that the animal would not be injured.

The ceramics used in the experiment were high-temperature industrial tile fragments. They are more resistant to breakage than the low-fired (and much older) archaeological ceramics, but we assumed that industrial ceramic fragments would be reasonable substitutes for archaeological ones, at least in terms of their weight and shape. Our concern was not with the degree of breakage induced by armadillos, but in the movement of objects within the sediment.

All flaked and broken material was incorporated into the experiment, but space constraints at the experimental setting did not allow sediment sieving, making the retrieval of very small pieces impractical. Our main concern, then, was with macroartifacts, defined as artifacts larger than -1.0 phi or $2 \mathrm{~mm}$, following Dunell and Stein (1989). The shapes and sizes of the lithics and ceramics used are within the ranges commonly found at archaeological sites: Ceramics were broken in maximum dimension ranging from 13 to $99 \mathrm{~mm}($ mean $=50.0 \mathrm{~mm}$; s.d. $=14.4$ ), and their weight between 1 and $121 \mathrm{~g}$ (mean $=24.1 \mathrm{~g}$, s.d. $=14.6$ ). Lithics presented both tabular ("flakes") and globular ("cores") shapes, with maximum dimensions 
Table I. Measures of sediment penetration resistence in the experimental setting.

\begin{tabular}{cc}
\hline West Unit $\left(\mathrm{kg} / \mathrm{cm}^{2}\right)$ & East Unit $\left(\mathrm{kg} / \mathrm{cm}^{2}\right)$ \\
\hline 0.25 & $>4.5$ \\
0.25 & 4.0 \\
0.75 & 4.25 \\
0.50 & 2.0 \\
0.25 & 2.5 \\
Mean $=0.40$; std. error $=0.10$ & Mean $=3.45 ;$ std error $=0.50$ \\
\hline
\end{tabular}

ranging from 14 to $113 \mathrm{~mm}($ mean $=53.0 \mathrm{~mm}$; s.d. $=16.8)$, and weight between 1 and $448 \mathrm{~g}$ (mean $=40.3 \mathrm{~g}$; s.d. $=54.6)$.

The matrix at the experimental site was composed of material from two sources: a very dry soil that was already inside the enclosure, and an extremely moist soil brought from elsewhere. The texture of these materials was the same: both are very poorly sorted clay (Appendix-Figures 19 and 20). However, because the materials were compacted in order to produce horizontal surfaces on which to lay the pieces, the final products were very different: a very compact moist sediment, and a friable dry sediment. The dry sediment was used to fill the West Unit, whereas the East Unit was filled with moist sediment. The differences in compactness were measured at five different points across each unit using a pocket penetrometer (Table I). The sediment at the East Unit was at least one order of magnitude more compact than the West Unit sediment. As will be shown, these differences in compactness greatly effected the armadillo's burrowing behavior. The animal used in the experiment was a female yellow armadillo (Euphractus sexcintus; length: 44.5 $\mathrm{cm}$; tail: $17.5 \mathrm{~cm}$; height: $15.0 \mathrm{~cm}$; maximum width: $22.0 \mathrm{~cm}$ ).

\section{Observations on the Burrowing Behavior of the Yellow Armadillo}

The manner in which different armadillo species make burrows can vary. The behavior we recorded for $E$. sexcintus is very similar to that described for $D$. novemcinctus by Taber (1945:218).

Both species of armadillos dig using a two-step procedure: The digging starts with the forelegs actively scratching the soil, the hind legs firmly planted to give support to the movement, until a certain amount of sediment accumulates underneath the animal's abdomen. The animal then arches the body and changes the pattern, expelling the sediment under its abdomen using the hind legs. The sediment is ejected and scattered away from the burrow entrance in the surface nearby, forming a fan. The procedure continues as the animal digs deeper into the ground, but as more sediment is expelled, a mound starts to form near the burrow entrance. The height of the mound, however, is maintained at a "comfortable" level. If too much sediment begins to accumulate, the armadillo climbs over the mound and scatters the sediment until its height is acceptable again. We were able to observe 
that all this burrow and mound maintenance was clearly responsible for considerable horizontal displacement of pieces.

In our experiment, armadillo activity was monitored and recorded through photographs and video at regular intervals during the entire period of the experiment. The animal started to dig immediately upon release, mixing many liters of sediment in a few minutes. During this brief period, it was already possible to see some pieces from the blue layer (20 cm depth) emerging on the surface, as well as ceramics from the surface being buried.

As previously noted, the burrowing activity was somewhat different depending upon compactness of the sediment. The animal chose to focus its burrowing activity in the West Unit, where the sediment was dryer and less compact. However, the weak sediment strength caused frequent collapse of the burrows, and the animal had to start a new burrow at another locality. After many failed attempts to dig a stable burrow in the West Unit, the animal centered its efforts on the East Unit, where the very cohesive sediment allowed good stability for the burrow. The animal dug fewer burrows at the East Unit, but the shape of the burrows was preserved. These differences in sediment compactness were very enlightening because it was possible to record two different results. At the West Unit, the results resemble what would be expected in a place where many burrows, going in different directions and crossing each other, were dug and then collapsed, causing artifacts from the ceiling of the burrows to move downwards, and artifacts from the floor to be buried. In the East Unit, the main result was the presence of an intact burrow not subject to collapse. The individual arrangement of pieces coming from different layers was observed, allowing a better understanding of the dynamics of artifacts inside armadillo burrows.

After 53 days the burrowing activity had nearly stopped, and the animal was removed from the enclosure.

\section{Excavation and Recording Procedures}

The enclosure was divided into four quadrants using two metric tapes to facilitate the positioning of individual artifacts. The retrieval of artifacts was accomplished by excavating the matrix with brushes to avoid displacement of the pieces. The experimental site was never trampled, and suspended boards were used to allow access to the farthest points of the enclosure. The horizontal $X$ and $Y$ coordinates for individual pieces were recorded in each quadrant. The $Z$ coordinate (depth) was recorded with an automatic level (Nikon Model S-2). The dip of the piece was then recorded by noting if its major axis was "sub-horizontal" (up to $45^{\circ}$ ) or "vertical" (more than $45^{\circ}$ ) position. Each piece was then given a number and bagged. Measures of length, width, thickness, and weight were recorded in the lab. All data were recorded on forms and subsequently stored in a computerized database. The grand total of recorded artifacts was 1406. This number excludes most pieces that were found in their original positions and therefore not subject to the recording procedures. 
Table II. Pearson's correlation between variables for ceramics.

\begin{tabular}{lcc}
\hline \multicolumn{1}{c}{ Ceramics } & Pearson's $r$ & Significance $p$ \\
\hline Depth $\times$ weight & 0.017 & 0.61 \\
Depth $\times$ length & 0.003 & 0.93 \\
Depth $\times$ width & 0.022 & 0.515 \\
Depth $\times$ thickness & -0.016 & 0.639 \\
\hline
\end{tabular}

\section{Methods of Data Treatment}

Data were analyzed statistically and graphically. Statistical procedures were used to answer questions regarding relationships between artifact size/weight and magnitude of displacement. Graphic displays were used to aid the visualization of the disturbance in three dimensions and to help in recognizing the effects of armadillo's burrowing activity on archaeological deposits.

\section{DISCUSSION}

\section{Statistics}

Individual data on artifact position, length, thickness, width, and weight for all lithics and ceramics (East and West units) were cross-tabulated against their vertical displacement to determine if significant correlations exist between these variables (Tables II and III). These results show that correlations are very weak, suggesting no preferential movement of either heavier, lighter, smaller, or larger pieces across the matrix, within the ranges of the parameters tested.

Another cross-tabulation was made between class of dip ("sub-horizontal" or "vertical") and the vertical displacement of the pieces. In this case, the absolute distance traveled by the pieces (either up or down) was clustered into classes (e.g., original range, $10-\mathrm{cm}$ displacement, $20-\mathrm{cm}$ displacement, etc.) and ranked against the percentage of pieces in vertical position for each displacement class using Spearman's rank coefficient. The result shows a very strong relationship between the variables (Spearman's $\rho=.96, .05>p>.01$ ), suggesting that the greater the displacement, the greater the probability that the artifact will rest with its major axis in an angle greater than $45^{\circ}$ (Figure 3).

Because the angle of dip can be a good indicator of post-depositional movement (e.g., Schiffer, 1987:270), we made a tabulation of the classes of dip for all displaced

Table III. Pearson's correlation between variables for lithics.

\begin{tabular}{lcc}
\hline \multicolumn{1}{c}{ Lithics } & Pearson's $r$ & Significance $p$ \\
\hline Depth $\times$ weight & -0.097 & 0.07 \\
Depth $\times$ length & -0.062 & 0.24 \\
Depth $\times$ width & -0.082 & 0.12 \\
Depth $\times$ thickness & -0.094 & 0.08 \\
\hline
\end{tabular}




\section{Displacement and class of dip}

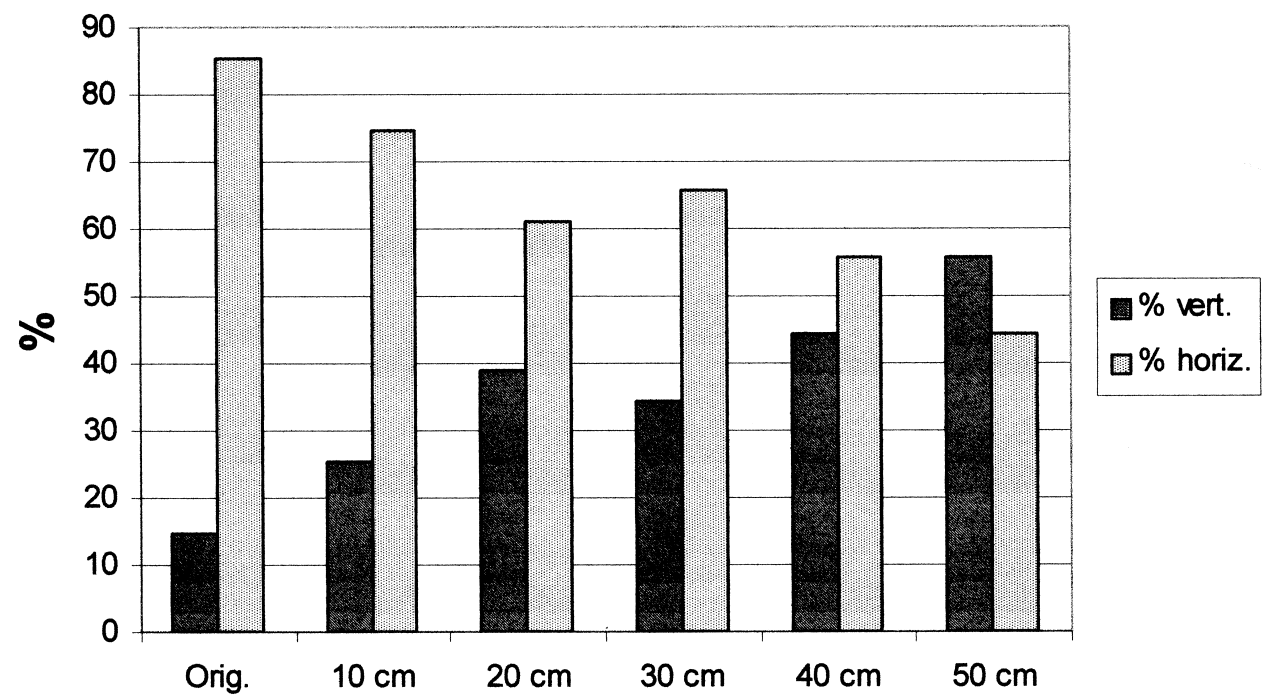

Figure 3. Tabulation of absolute vertical displacement against percentage of pieces in vertical position $\left(>45^{\circ}\right)$. The correlation is very strong $(r s=.96, .05>p>.01)$.

pieces (Table IV), not taking into account pieces that were horizontal due to their original placement. Pieces labeled as "undetermined" are ones whose three axes had dimensions very close to each other, therefore precluding dip observations.

Because some of the classes have a small sample size, we lumped them into two classes: displaced ceramics and displaced lithics. The result is an overall frequency of artifacts that came to rest in "vertical" and "sub-horizontal" positions after being disturbed (Table V).

A chi-square test suggests that the difference in frequencies of the positioning of

Table IV. Positioning of displaced pieces by color.

\begin{tabular}{lcccccc}
\hline \multicolumn{1}{c}{ Material/Color } & Sub-Horizontal & \% Sub-Horizontal & Vertical & \% Vertical & Undet. & \% Undet. \\
\hline $\begin{array}{l}\text { White and yellow } \\
\quad \text { ceramics }\end{array}$ & 612 & 70.10 & 246 & 28.18 & 15 & 1.72 \\
Blue ceramics & 27 & 54.00 & 23 & 46.00 & 0 & 0.00 \\
Green ceramics & 20 & 68.97 & 9 & 31.03 & 0 & 0.00 \\
Red ceramics & 7 & 77.77 & 2 & 22.22 & 0 & 0.00 \\
White lithics & 32 & 94.12 & 2 & 5.88 & 0 & 0.00 \\
Blue lithics & 192 & 71.38 & 73 & 27.14 & 4 & 1.49 \\
Green lithics & 2 & 33.33 & 4 & 66.67 & 0 & 0.00 \\
\hline
\end{tabular}


Table V. Lumped frequencies of all displaced ceramics and lithics.

\begin{tabular}{lcccccc}
\hline Material & Sub-Horizontal & \% Sub-Horizontal & Vertical & \% Vertical & Undet. & \% Undet. \\
\hline Ceramics & 666 & 69.30 & 280 & 29.14 & 15 & 1.56 \\
Lithics & 226 & 73.14 & 79 & 25.57 & 4 & 1.29 \\
\hline
\end{tabular}

lithics and ceramics is not significant $\left(\chi_{2}=1.655, p=0.437\right)$. The data in Table $\mathrm{V}$ also show that on average $30 \%$ of all displaced artifacts came to rest with their major axis on angles higher than $45^{\circ}$ from the horizontal plan (Figure 5). It is important to note that $30 \%$ of the pieces will rest at very steep angles, but this does not mean that the other $70 \%$ will rest in a nearly horizontal plane since our measure of "sub-horizontal" included all pieces resting at angles up to $45^{\circ}$.

\section{Graphics}

In order to visualize possible patterns and understand the results of the armadillo's burrowing action, a computer program, SURFER (Golden Software, 1994), was employed. SURFER is a three-dimensional graphics program that allows the plotting of individual artifacts by means of their spatial coordinates.

\section{Surface Plots}

Surface plots are "surfaces" generated by taking into account the three-dimensional position of individual pieces and linking them by means of a gridding algorithm (Golden Software, 1994). In this case, we used triangulation with linear interpolation, the same method used to interpolate contour lines in topographic maps. The purpose was to generate a post-turbation topography, or a "deformed surface" that would depict the armadillo's action on an originally flat surface. Hence, these surfaces may be regarded as isochronous planes linking "contemporaneous" artifacts in three dimensions.

Figures 4 and 5 show the surfaces generated by the artifacts from the two most turbated layers (white and yellow ceramics and blue lithics), from two different viewpoints. If one imagines the original surfaces as planes, these post-turbation surfaces are impressive (it should be noted that these surfaces are not shown with any vertical exaggeration). Figures 6 and 7 show these same surfaces in plan, with the contour lines representing depths in centimeters.

\section{Vertical Plots}

The axial projection of the pieces against a vertical plane ("backplots") was also examined (Figures 8-11). At first glance, the most striking feature is the almost complete mixing of the two uppermost layers, as can be seen in Figure 8 . While it is sometimes possible to discern two distinct layers, most of the profile presents a heavy mixing between them. Figure 9 shows a disentangled image of the two layers that were more strongly mixed: the surface layer (white and yellow ceramics) and 

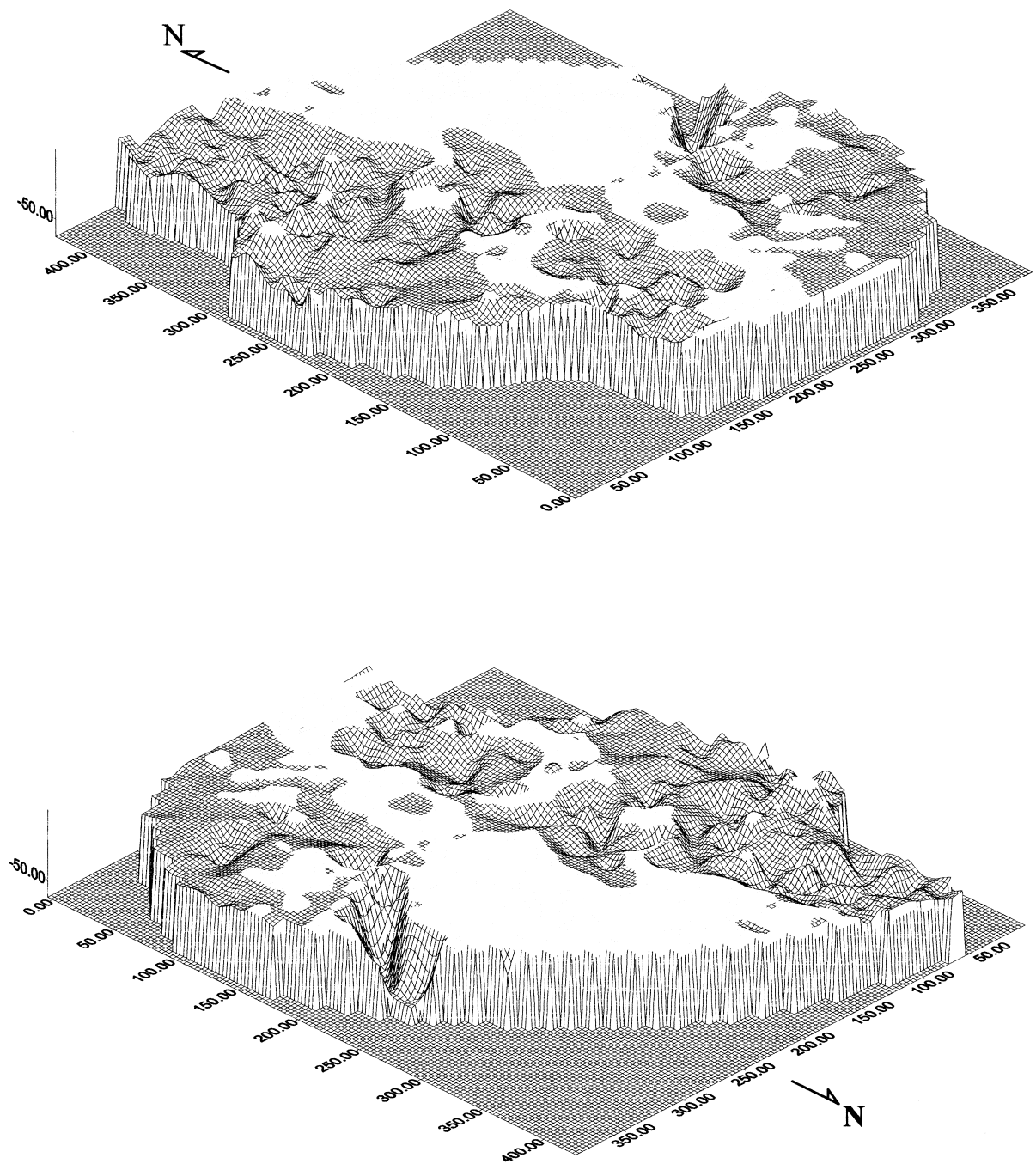

Figure 4. Surface generated by the positioning of white and yellow pieces (ceramics, surface) after bioturbation, seen from two different perspectives. Light colored area shows the original level. Horizontal and vertical scale 1:1. 

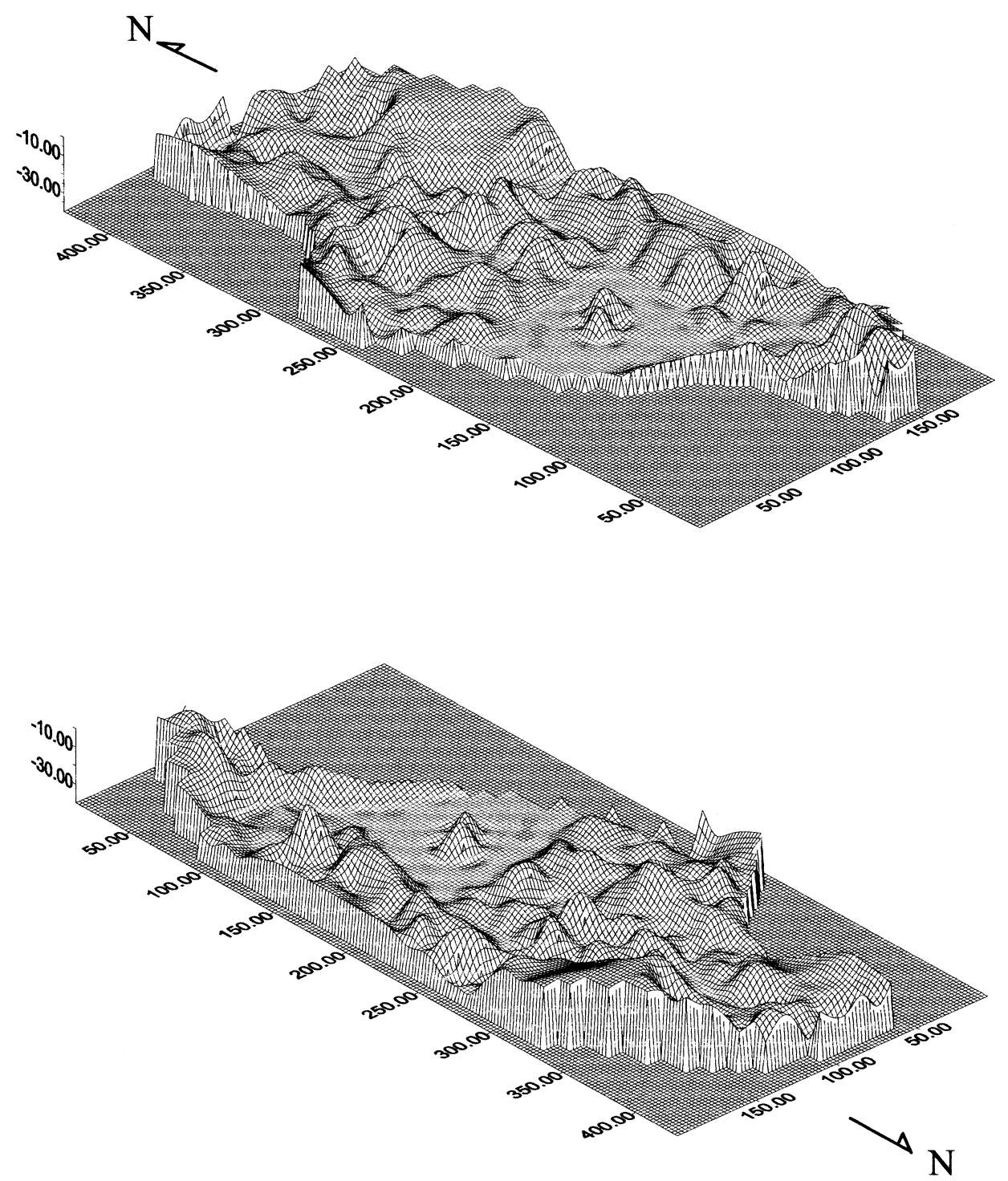

Figure 5. Surface generated by the positioning of blue pieces (lithics, $20 \mathrm{~cm}$ depth) after bioturbation, seen from two different perspectives. Light-colored area denotes the original level. Horizontal and vertical scale 1:1. 


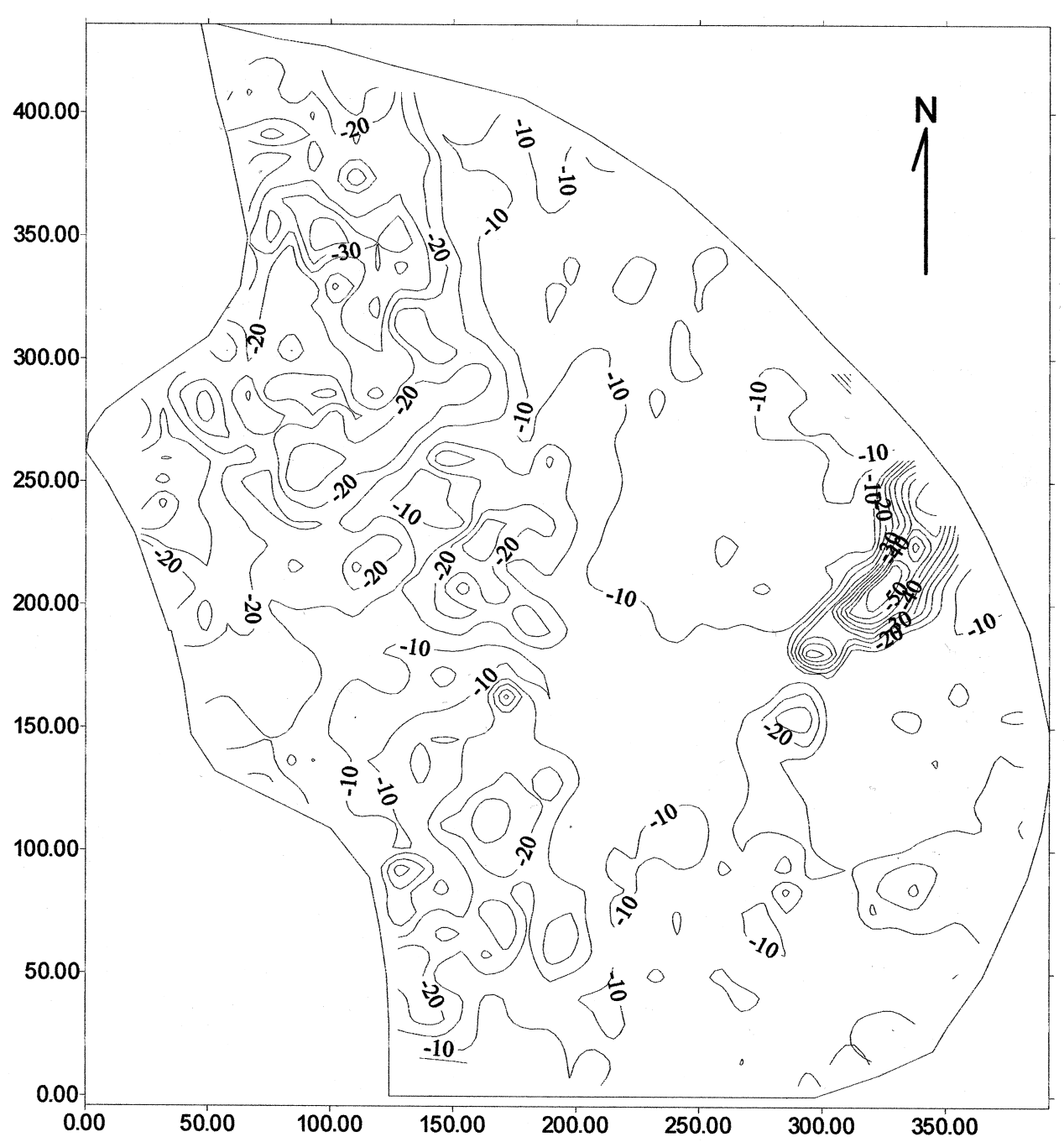

Figure 6. Contour map of the surface showing the position of the white and yellow pieces, originally placed at the surface, after bioturbation. All numbers in centimeters. 


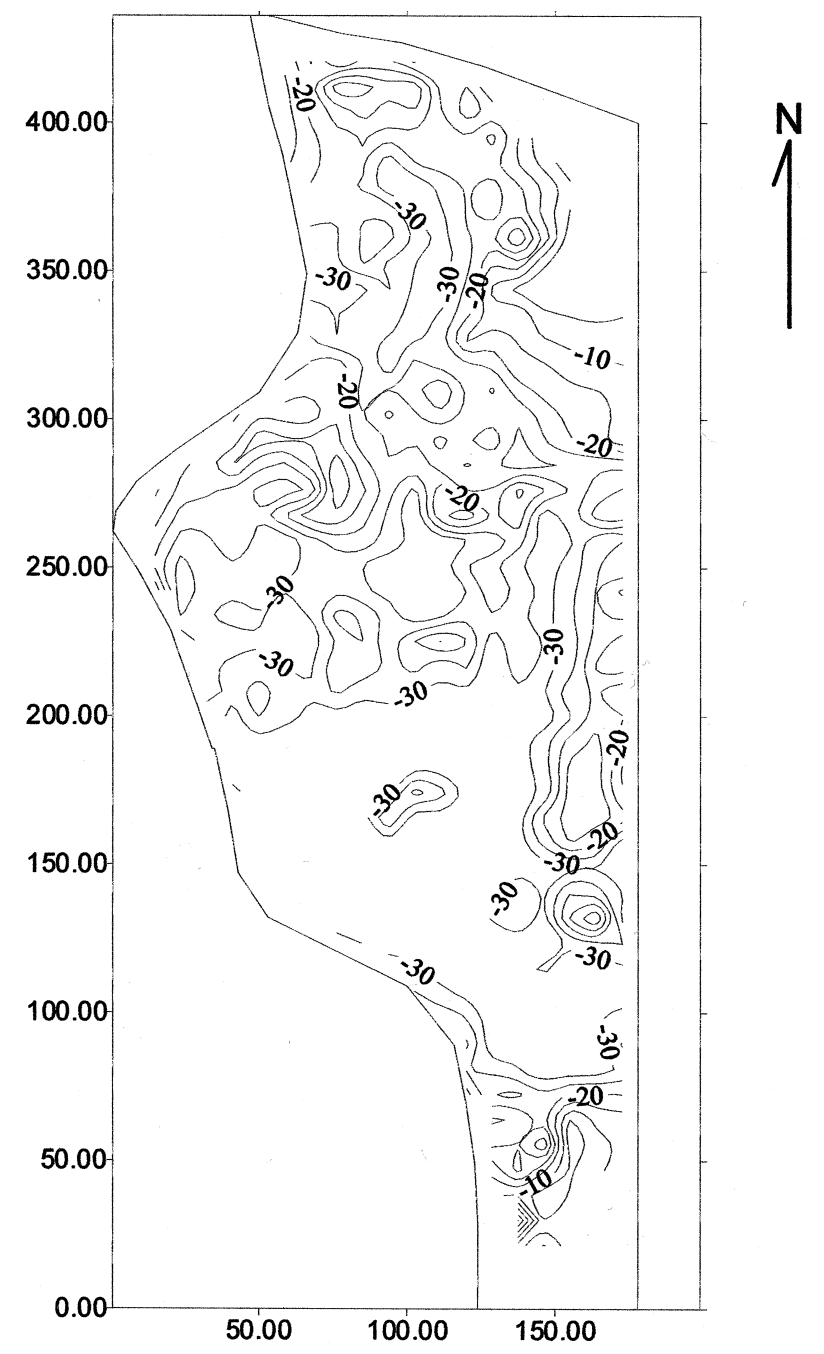

Figure 7. Contour map of the surface showing the position of the blue pieces, originally placed at 20 $\mathrm{cm}$ depth, after bioturbation. All numbers in centimeters. 


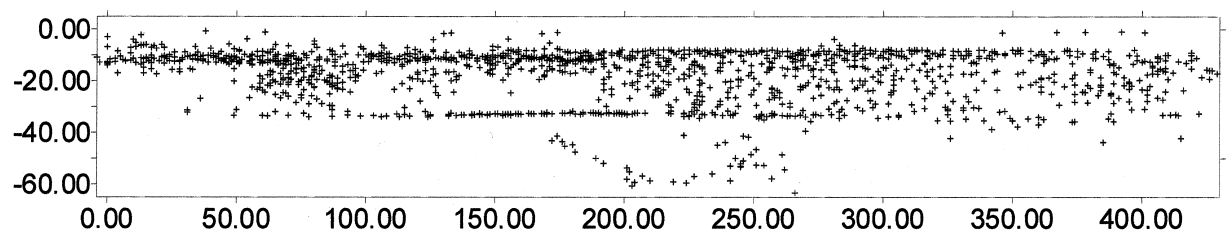

Figure 8. General profile showing all recovered pieces after bioturbation. All numbers in centimeters.

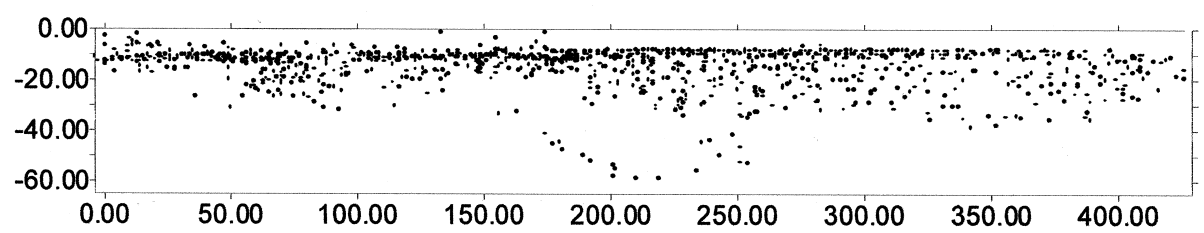

First layer - white / yellow ceramics (surface)

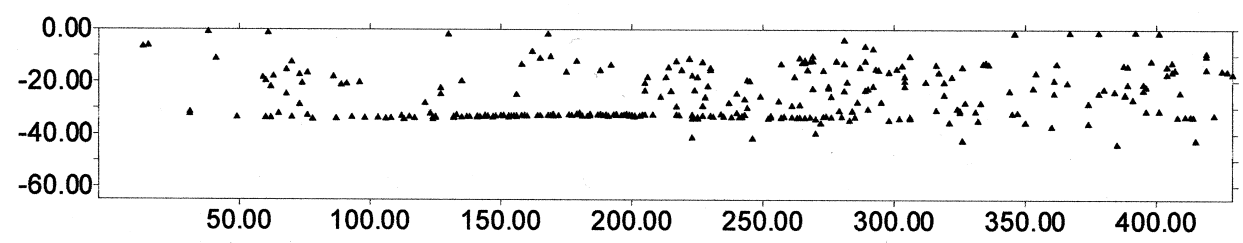

Second layer - blue lithics $(20 \mathrm{~cm})$

Figure 9. Comparison between layers after bioturbation. Vertical and horizontal scale 1:1. All numbers in centimeters. 


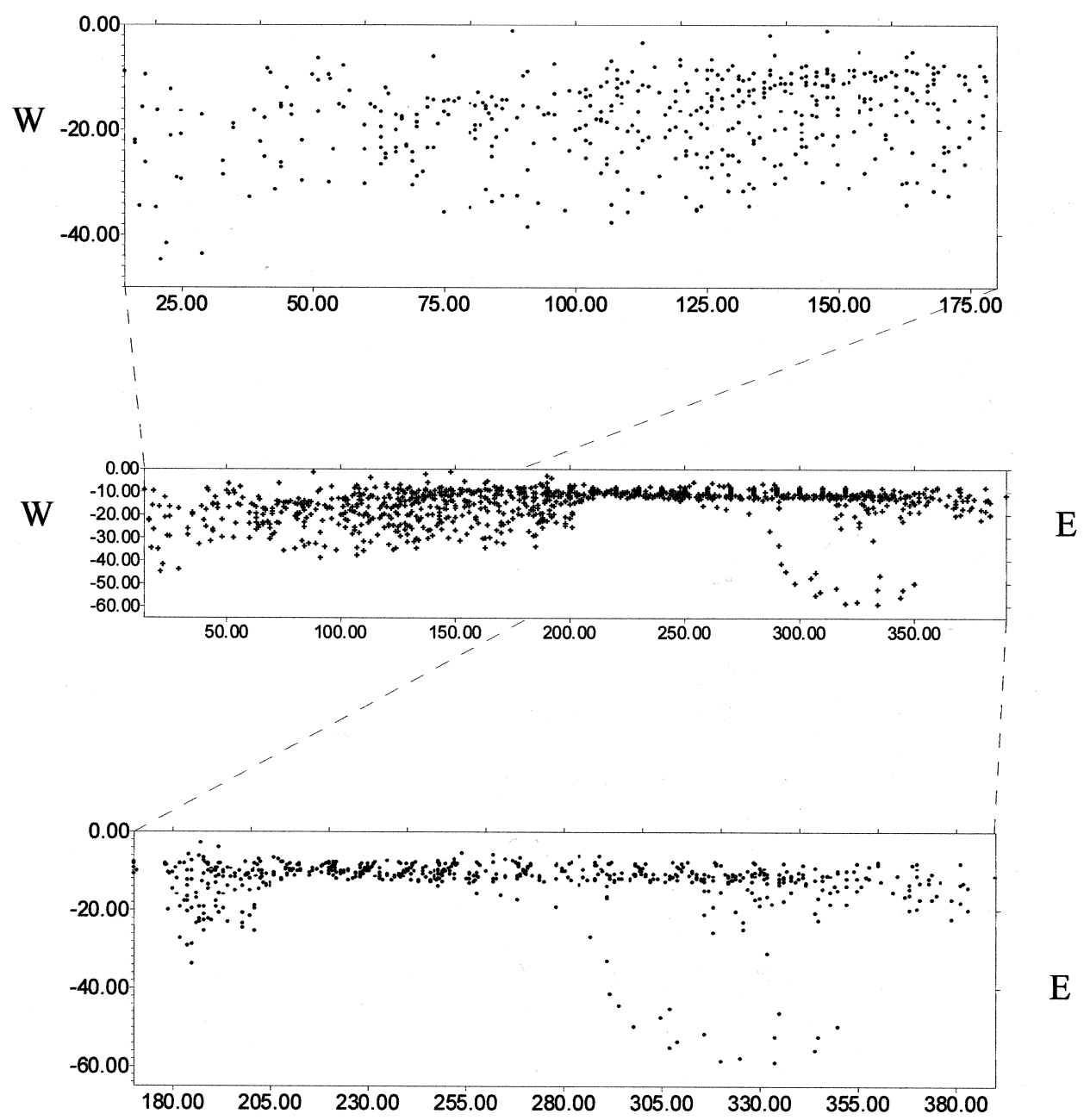

Figure 10. Profile of the west quadrant, E-W direction, white/yellow ceramics. Vertical and horizontal scale 1:1. All numbers in centimeters.

the layer $20 \mathrm{~cm}$ below surface (blue lithics). This image shows that not only were the white and yellow pieces displaced downward, but that a large proportion of the blue pieces was moved upward. This pattern suggests that the effects of armadillos on archaeological material is two-directional: Pieces are moved when the animal excavates its burrow, and artifacts are displaced downward when they fall into the burrows or when burrows collapse.

The vertical projections also show that mixing was more intense in the West Unit. Figures 10 and 11 show the vertical displacement of ceramics that were orig- 


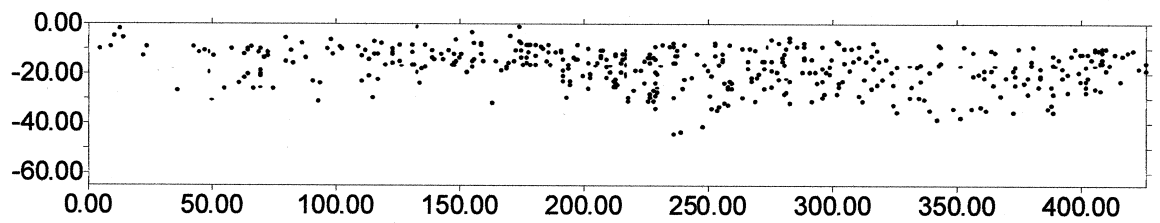

West Quadrant

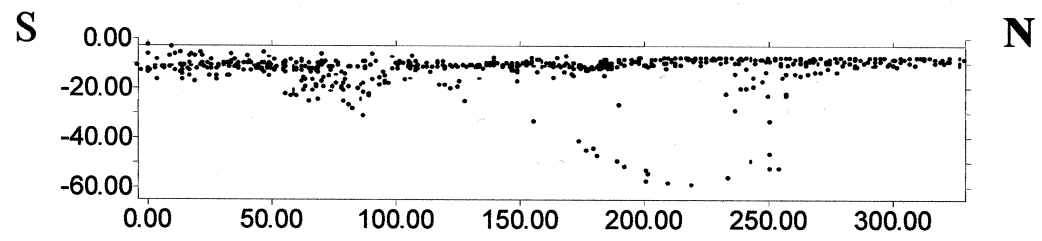

\section{East Quadrant}

Figure 11. Profiles N-S of the West and East quadrants, white/yellow ceramics. Vertical and horizontal scale 1:1. All numbers in centimeters.

inally laid on the surface. These patterns are probably related to the nature of the sediment. Specifically, the armadillo tended to dig a greater number of burrows in the dry, friable soil in the West Unit, causing greater vertical displacement of artifacts in that unit compared to the East Unit.

The vertical projections also show the outline of a burrow that remained intact. The burrow is marked by a line of artifacts trending downwards to form a basinshaped feature (Figures 8-11). It is interesting to note that this burrow outline appears in both directions $(\mathrm{N}-\mathrm{S}$ or $\mathrm{E}-\mathrm{W})$ as seen in the bottom of Figures 10 and 11.

Even with all the mixing, it is important to note that when the frequency of pieces is plotted against depth, there is a clear peak near the level where the pieces were originally placed (Figures 12 and 13).

\section{Horizontal Plots}

As noted earlier, objectives of this study did not include an assessment of the horizontal displacement of the pieces. However, because the pieces were originally placed at regular intervals and we had point-provenience data after turbation, it was possible to plot them in plan and to record changes in the original pattern. Initially, the experimental deposit was graphically cut into 10-cm-thick layers. In 


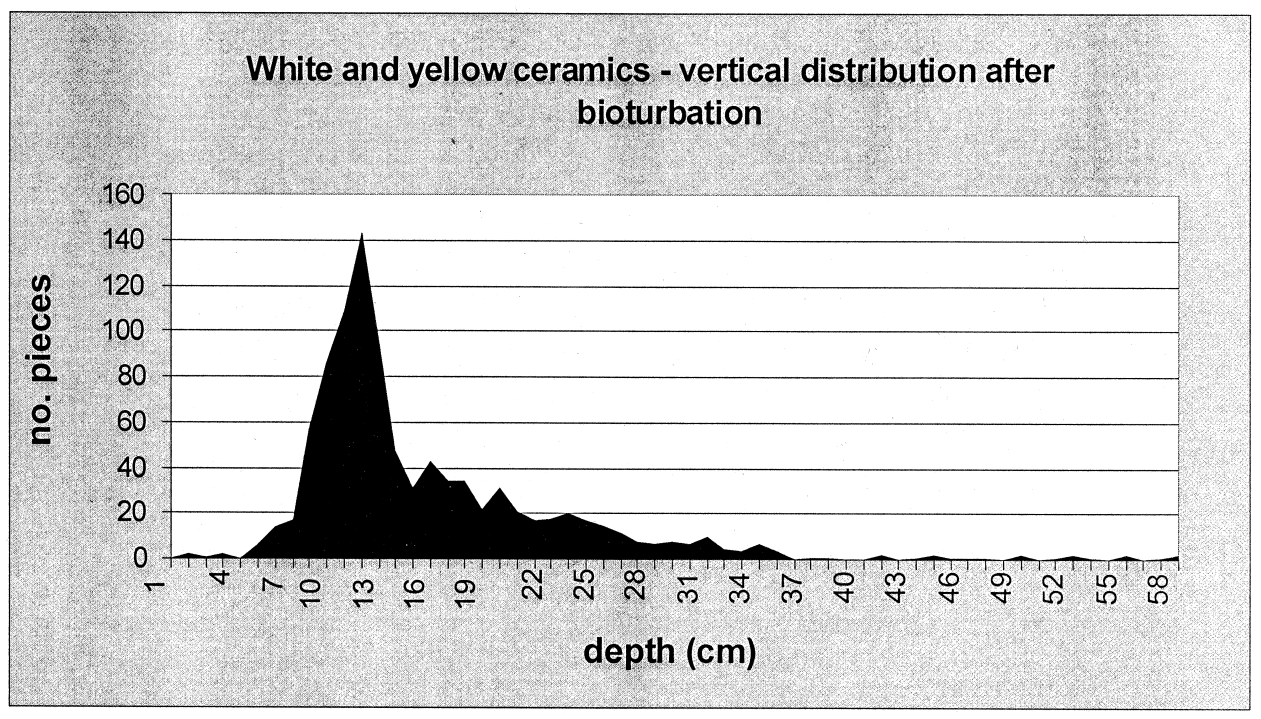

Figure 12. Vertical distribution of white and yellow ceramics after bioturbation. The peak shows a greater concentration of pieces around the original level (surface, or about $10 \mathrm{~cm}$ below datum).

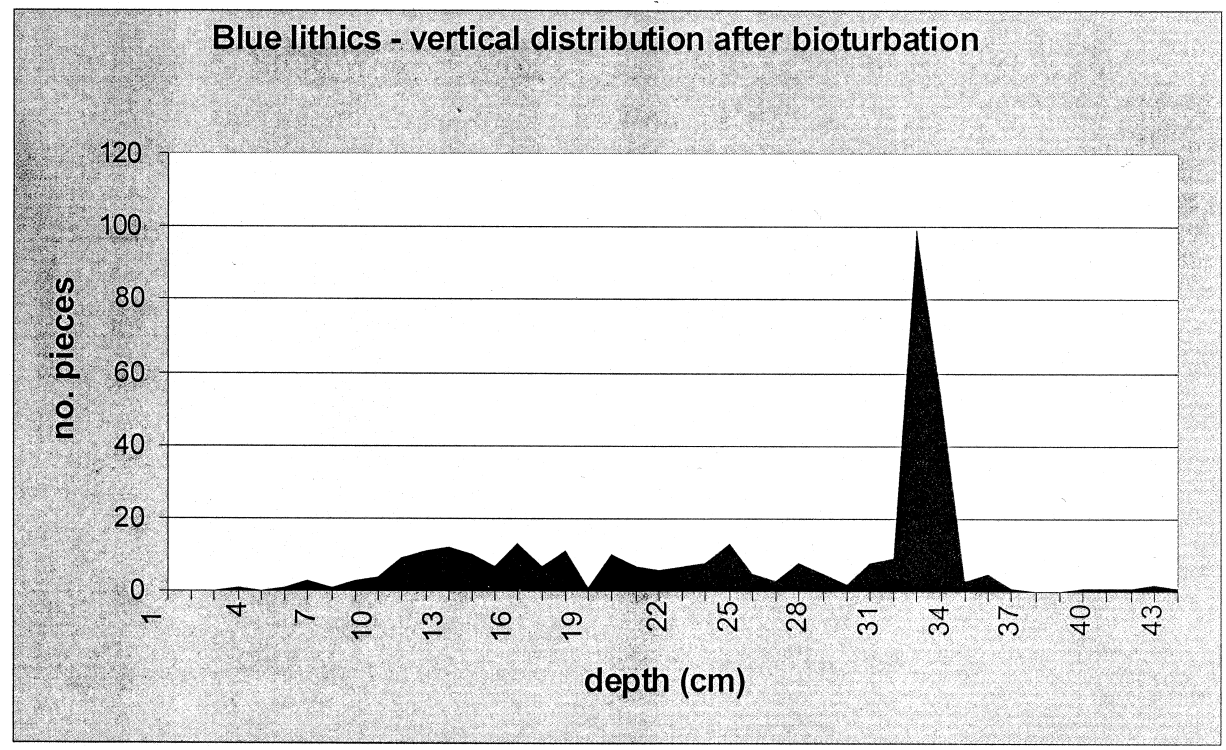

Figure 13. Vertical distribution of blue lithics after bioturbation. The peak shows a greater concentration of pieces around the original level ( $20 \mathrm{~cm}$ depth, or about $30 \mathrm{~cm}$ below datum). 


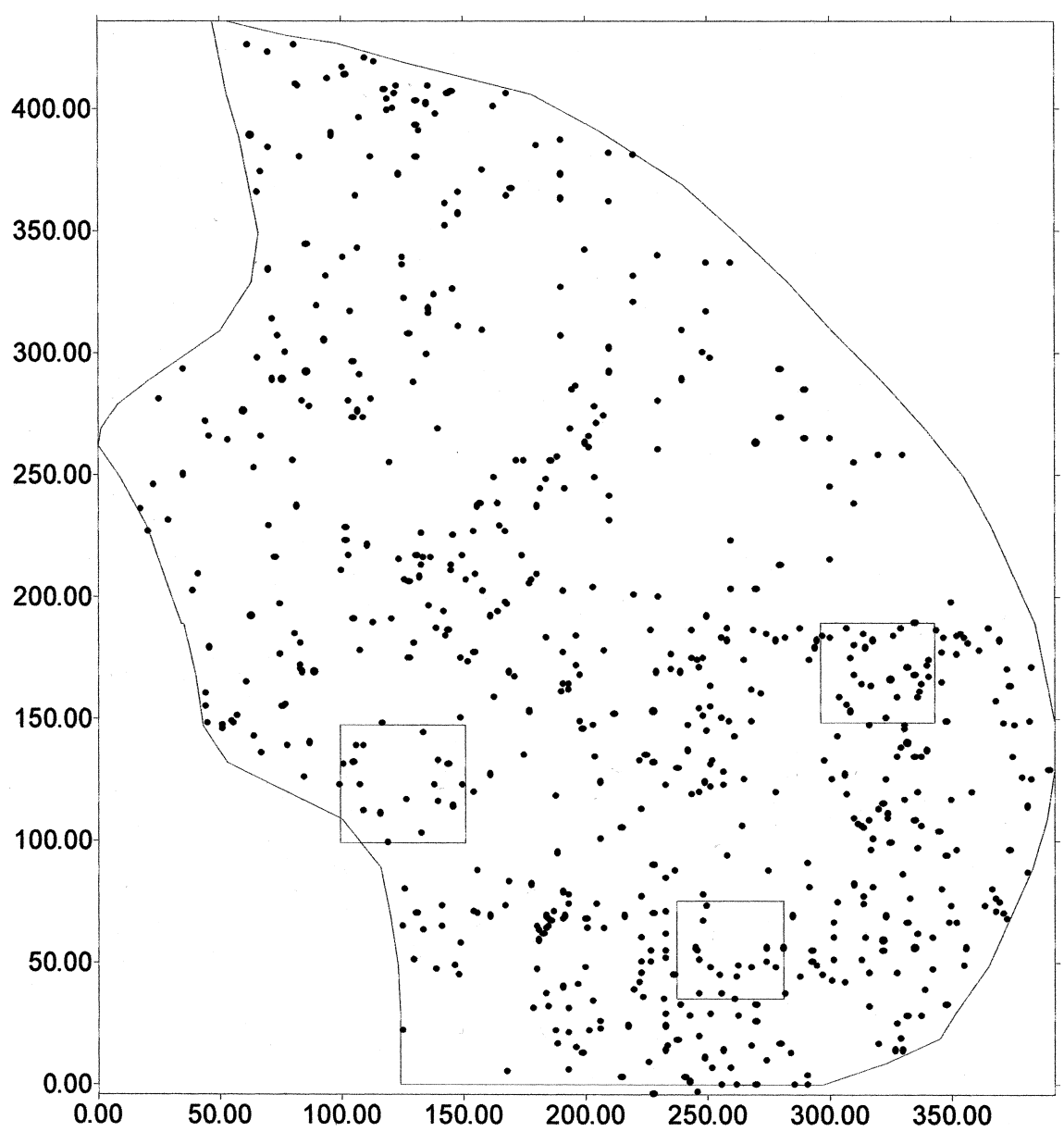

Figure 14. Plan showing the position of all artifacts resting between 10 and $20 \mathrm{~cm}$ depth (below datum). Rectangles assign fan-shaped concentrations. All numbers in centimeters.

Figure 14, for example, it is possible to see how the ceramics that were originally placed on the surface are distributed in plan as if they were excavated in a $10 \mathrm{~cm}$ arbitrary level. In some places, the pieces are scattered, forming crescents that could be attributed to the armadillo's burrowing action. It is also possible to detect places where the ceramics are scattered and others where they are concentrated. This led us to try even thinner slices ( $1 \mathrm{~cm}$ thick) of the deposit to see how the spatial distribution of the pieces would appear at the surface as if the site was excavated following a given level. The result is very much like an occupation floor; pieces are widely scattered in some places and concentrated in others. In order to provide a more rigorous description of these patterns, we ran a k-means clustering algorithm (cf. Kintigh and Ammerman, 1982; Simek and Larick, 1983). The choice 
of $k$-means was made because of its wide application in archaeology (see Wandsnider [1996:337] for a discussion on the topic). For reasons of space, we present only the clustering runs made for a $1 \mathrm{~cm}$ slice delimited between 10 and $11 \mathrm{~cm}$ below surface. Figure 15 shows the spatial pattern of artifacts at this level. Figure 16 shows the plot of log (\%SSE) against the number of clusters for the $10-11 \mathrm{~cm}$ level, together with the results of two runs made on randomized data. According to the "heuristic approach" advocated by Kintigh and Ammerman (1982), the fact that the summed standard error (SSE) for the actual data is systematically smaller than the SSE for random data indicates the clustered character of the points at the $10-11 \mathrm{~cm}$ level. Another fact that can be observed in this graphic is that the better resolution recognizes eight clusters, where the log (\%SSE) drops significatively.

The main conclusion drawn from the analyses of horizontal plots is that the armadillo's action followed a clear pattern, transforming a uniform distribution of pieces into a clustered one. Obviously the pattern of dispersal is masked, or a new appearance is imparted to it, depending on the specific recording procedures. For example, the horizontal slice at our "site" transformed the otherwise wavy pattern of dispersal shown in the surface plots (see Figures 4 and 5) into a series of clusterand-void patterns that could be incorrectly interpreted as activity areas or occupation floors (Figure 15).

\section{Additional Observations}

The only burrow that was intact by the time we started recording data was excavated using a somewhat different procedure. To avoid the collapse of the ceiling during the excavation, which could induce spurious movement of artifacts, fine white sand was carefully introduced inside the burrow with a funnel. The color of the sand contrasted with the reddish color of the sediment, allowing easy delimitation of the burrow's boundaries and retrieval of the artifacts resting on its floor.

We found artifacts from all four layers resting inside the burrow, as would be expected. However, it is interesting to note that some artifacts from the surface layer were deep inside the burrow, which provides additional hints not only about vertical movement but also about horizontal movement, since these artifacts could only be intruded into the burrow through its only opening. Figures 17 and 18 show the general aspects of the burrow. Figure 17 shows a profile of the burrow and the distribution of the yellow artifacts originally placed at the surface. Most of them are several decimeters from the entrance, in the lower part of the burrow. They show an average vertical and horizontal displacement of 40 and $120 \mathrm{~cm}$, respectively. If we take a point in the center of the entrance as reference, the yellow pieces are on average $125 \mathrm{~cm}$ from it in a straight line. One extreme case is an artifact at $174 \mathrm{~cm}$ in straight line distance from the entrance.

\section{CONCLUSIONS}

This experiment shows not only that some of the assumptions commonly held about the impact of armadillos on archaeological deposits are true, but, more im- 
ARMADILLOS IN THE MOVEMENT OF ARCHAEOLOGICAL MATERIALS

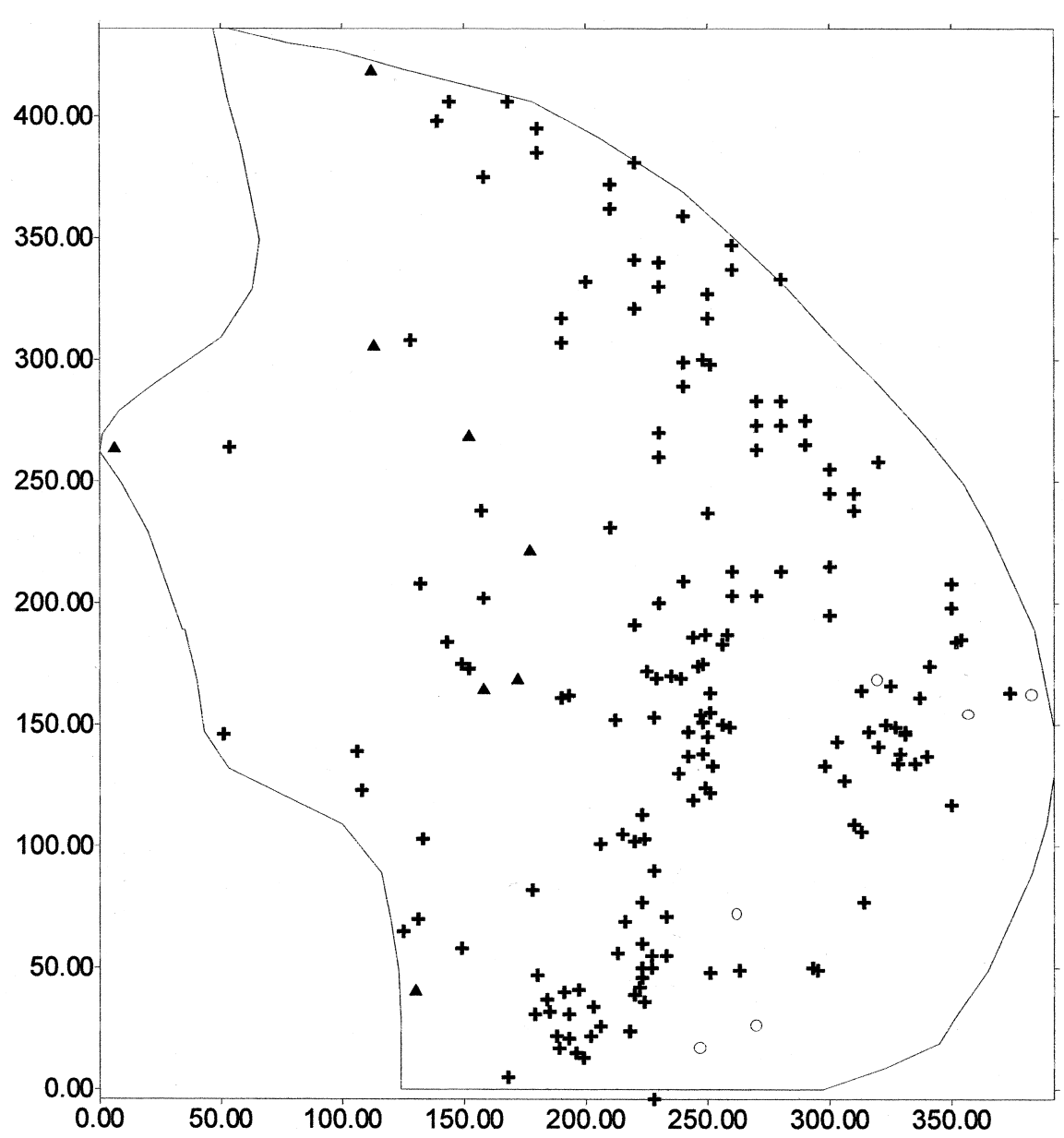

\section{- Blue lithics}

HWite/Yellow ceramics

\section{Blue ceramics}

Figure 15. Plan showing the position of all artifacts found in a 1-cm slice, between 10 and $11 \mathrm{~cm}$ below datum. All numbers in centimeters. 
k-Means for $10-11 \mathrm{~cm}$ level

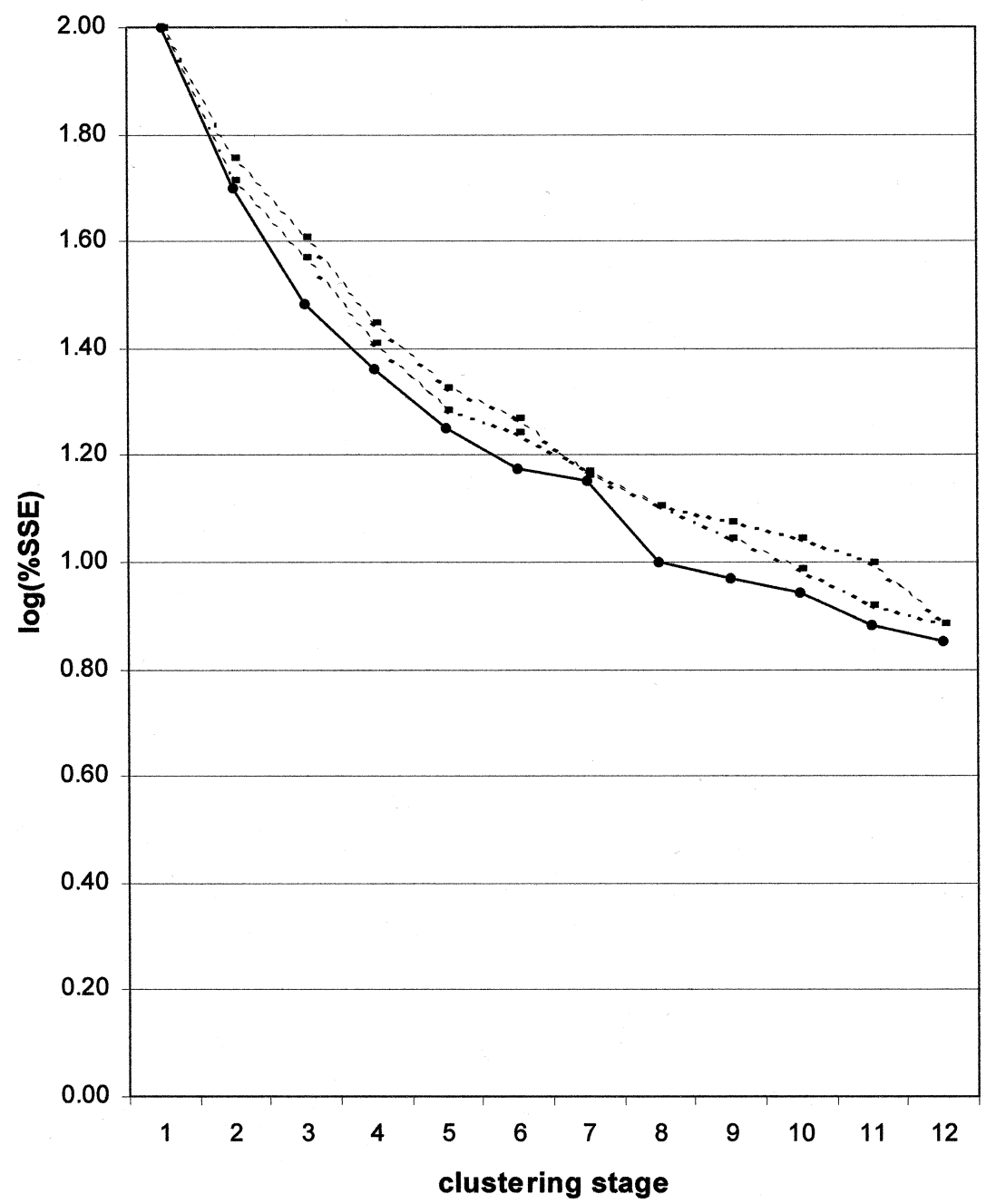

Figure 16. Results of k-means. Plot of $\log (\% \mathrm{SSE})$ against clustering stage for level $10-11 \mathrm{~cm}$ (points connected with a solid line) and two runs made on randomized data (dashed lines). Values of SSE are consistently smaller than expected for random values, suggesting a clustered pattern. 


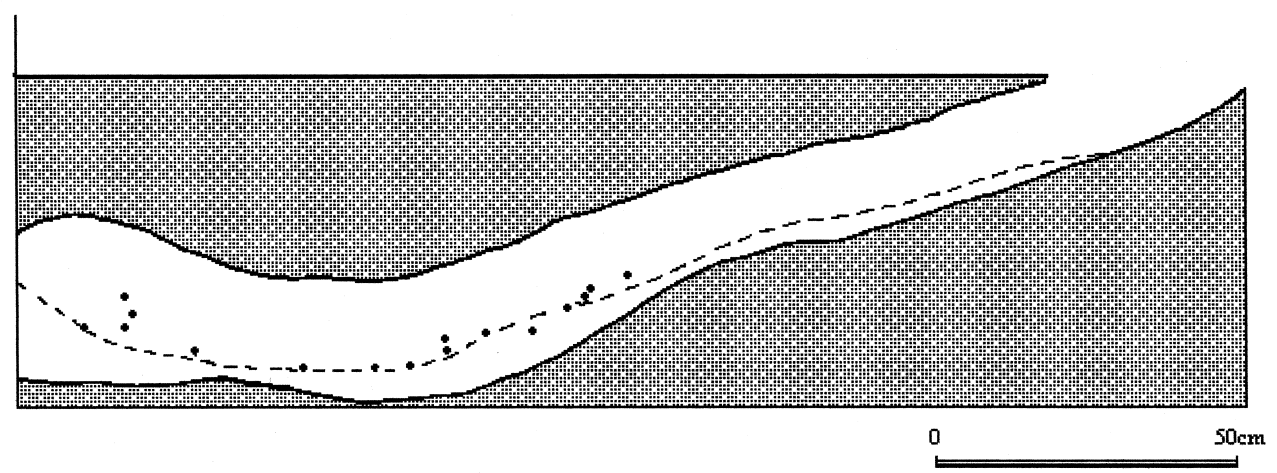

Figure 17. Profile of the armadillo burrow, marked by solid lines. Dashed lines represent the loose soil, and dots mark the position of pieces that came from the surface via burrow entrance. No vertical exaggeration.

portantly, it quantifies the magnitude of this impact. Some of our findings have never been reported in the literature, such as the fact that armadillos can translocate artifacts downward to great depths as well as expel them towards the surface. We realize that the focus of our study warrants more research and other methods of analysis. In retrospect, we would have measured angles of dip of artifacts more systematically, instead of lumping them into two classes. Also, numbering the experimental pieces would have allowed us to investigate horizontal displacement more systematically. Finally, additional data on armadillos in natural settings would be very helpful, especially data on burrow length, depth, and average number of burrows per individual.

Our findings support the following conclusions. First, armadillos are responsible for vertical movement of archaeological materials, but the displacement of artifacts does not appear to be systematic. The animal can move buried artifacts either up or down the profile. Of course, pieces lying on the surface prior to a given burrowing event can only move down. Once they move downward, they may go even deeper or be ejected to the surface again.

Second, armadillos can mix cultural horizons positioned at least $20 \mathrm{~cm}$ apart. Even so, the vertical distribution of artifacts shows a unimodal pattern with a peak around the original level of the pieces; i.e., there is a loss on the point provenience of the artifacts, but the general pattern of superposition of materials is retained. This fact has important implications for understanding site formation processes and artifact dynamics within archaeological deposits, and by extension about the kind of fine-grained information we should pursue.

Third, it was possible to observe some spatial patterning that may be recognizable in archaeological settings. On the vertical plan, a "hook-like" pattern was cre- 


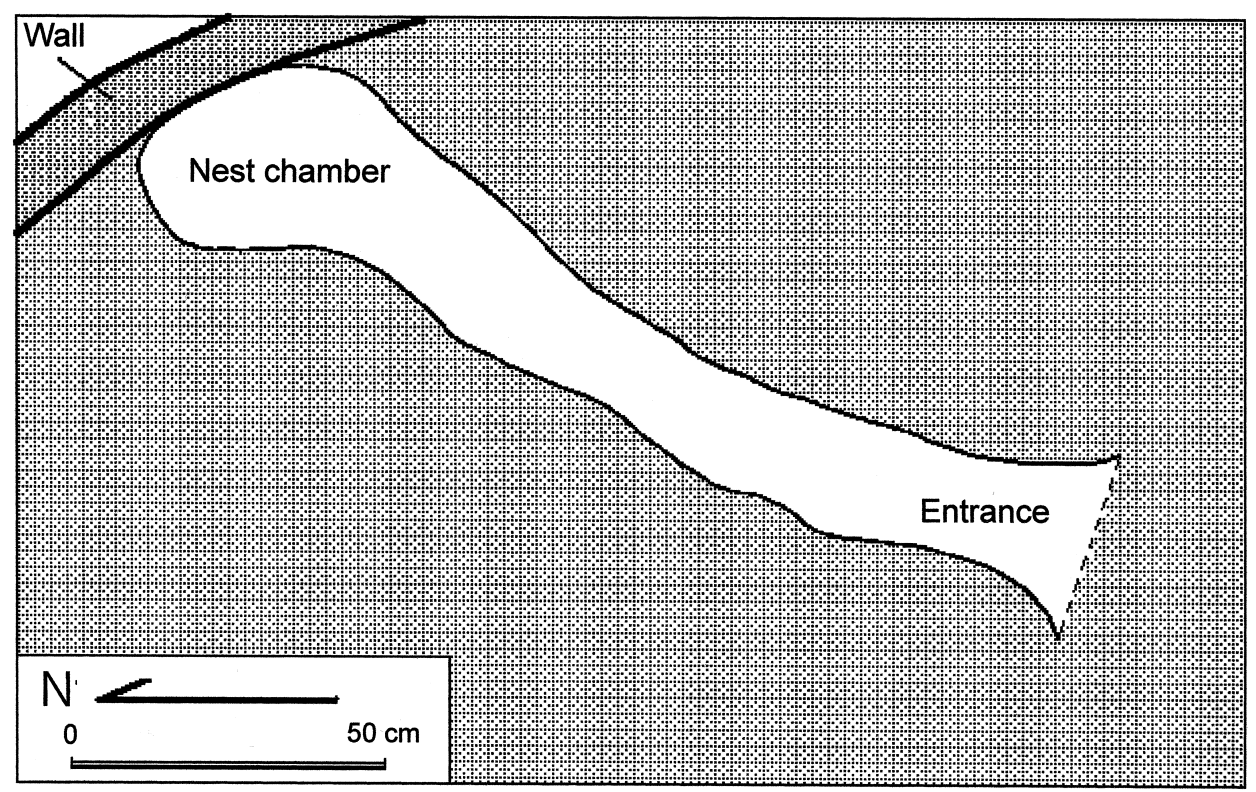

Figure 18. Plan view of the armadillo burrow.

ated by the pieces lying on the floor of the burrow. On the horizontal plan, it is possible to observe some crescent-shaped features attributable to the animal's digging action.

Fourth, there is no significant correlation between size, shape, or weight of the artifacts and amount of displacement, at least for specimens within the size range used in this study.

Finally, pieces displaced by armadillos tend to rest with their major axis tilted in relation to the horizontal plan. On average, as much as $30 \%$ of the displaced pieces will show angles of more than $45^{\circ}$. The greater the displacement, the more likely the artifact will rest in a more vertical position.

What this experiment and many others suggest is that tight, point-provenience control of artifacts is needed if we want to understand the factors accounting for the nature of a given archaeological deposit. In this context, refitting is an indispensible tool because data on the magnitude of post-depositional movement can only be assessed by this method (e.g., Villa, 1982a, 1982b; Villa and Courtin, 1983; Arts and Cziesla, 1990; Bollong, 1994). Computer treatment of the data is also very important for dealing with massive spatial information. Programs that allow the visualization of deposits and the artifacts within them in three dimensions are an invaluable resource (Kroll and Price, 1991:303). 


\section{APPENDIX: GRAIN SIZE ANALYSIS OF THE SEDIMENTS USED IN THE EXPERIMENT}

\section{West Unit}

Dry, soft sediment. Penetration resistence $=0.4 \pm 0.10 \mathrm{~kg} / \mathrm{cm}^{2}$

Granulometric characterization: clay ( Soil Survey Staff, 1975)

Grain size \% in weight:

Gravel $=0.15 \%$

Sand $=46.52 \%$

Silt $=6.23 \%$

Clay $=47.09 \%$

Mean grain size $=4.6 \mathrm{phi}$

Standard Deviation $=2.9$ phi-very poorly sorted $($ Folk, 1974)

\section{East Unit}

Moist, hard sediment. Penetration resistence $=3.45 \pm 0.50 \mathrm{~kg} / \mathrm{cm}^{2}$

Granulometric characterization: clay ( Soil Survey Staff, 1975)

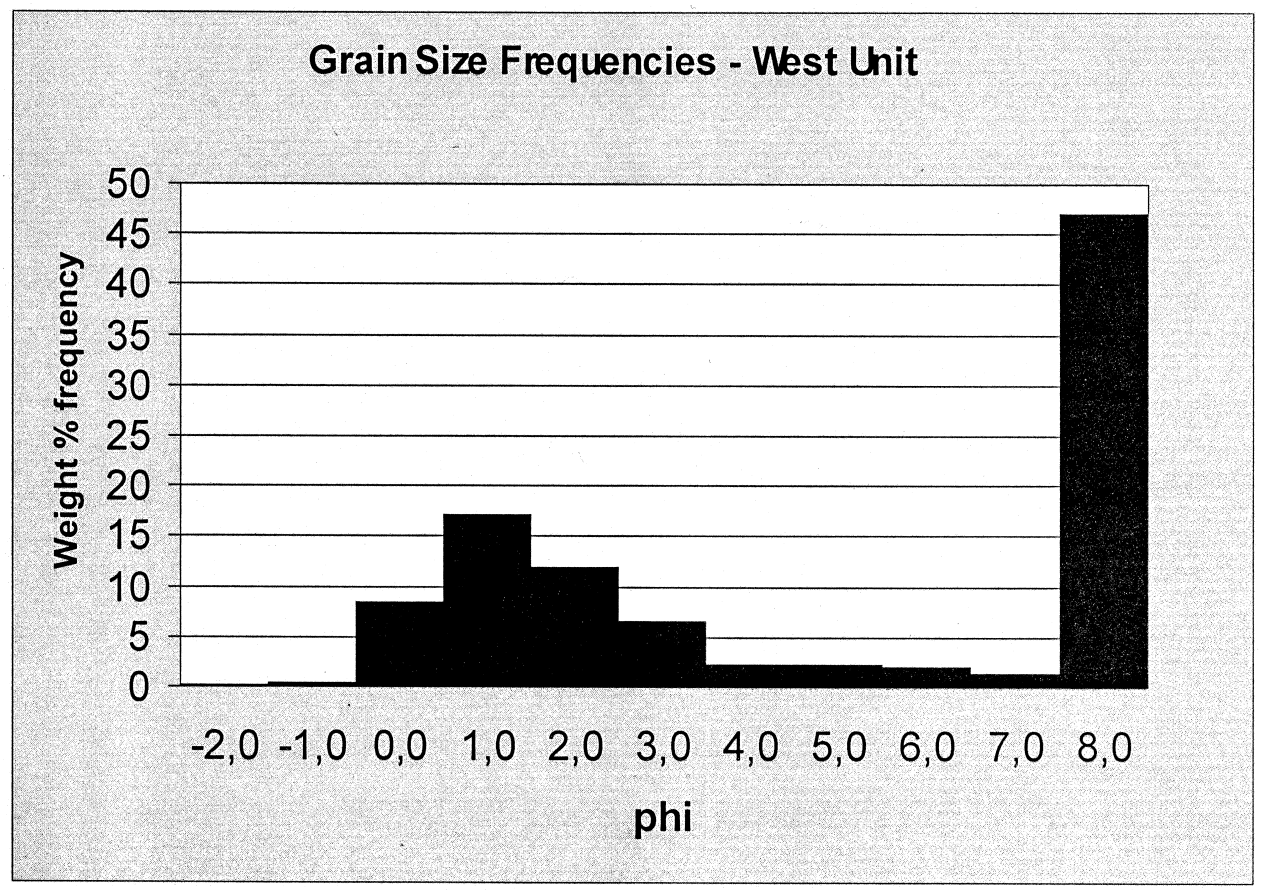

Figure 19. West Unit grain size frequencies. 


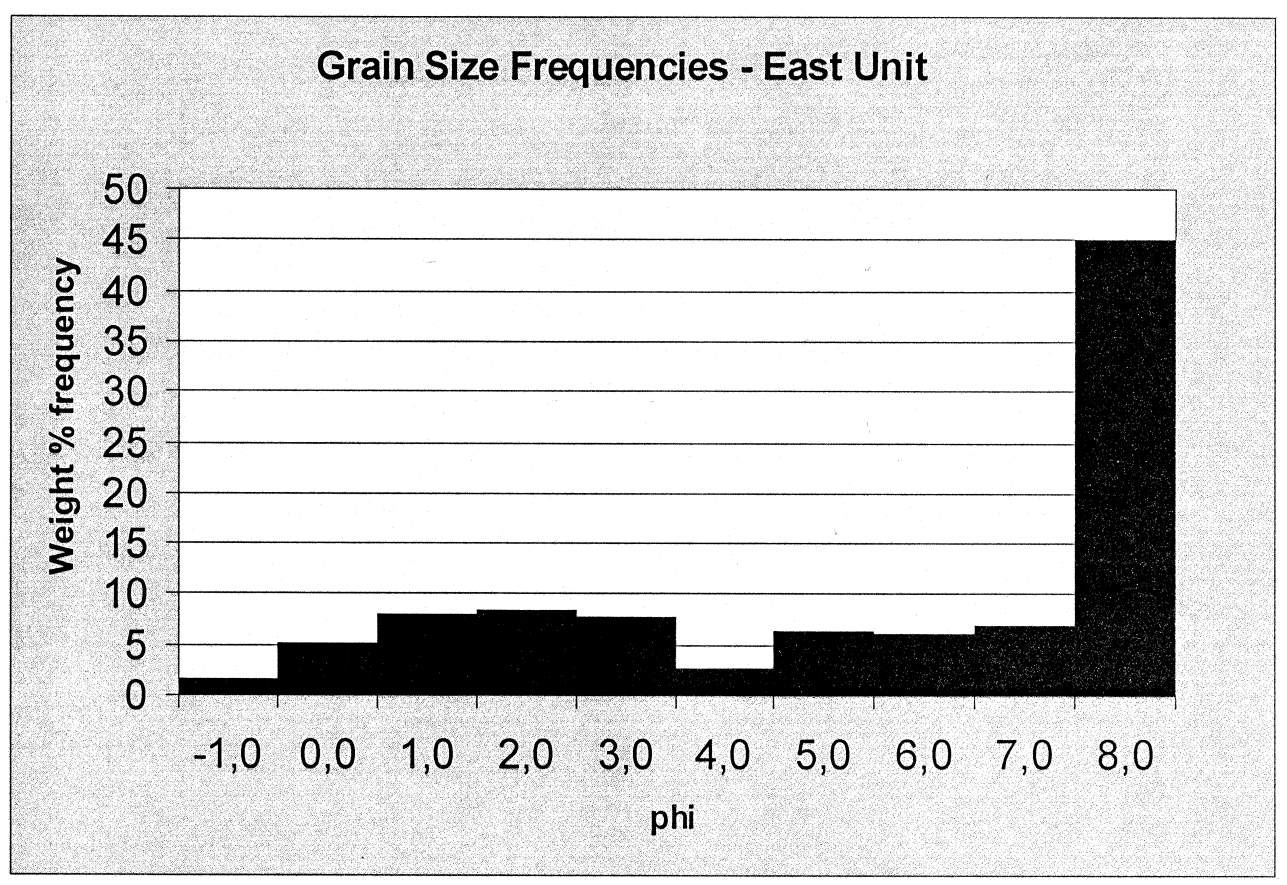

Figure 20. East Unit grain size frequencies.

Grain size \% in weight:

Gravel $=0.95 \%$

Sand $=31.10 \%$

Silt $=22.29 \%$

Clay $=45.11 \%$

Mean grain size $=5.0$ phi

Standard Deviation $=2.8$ phi - very poorly sorted $($ Folk, 1974)

We would like to thank Dr. Faiçal Simon, chief veterinarian of the São Paulo Zoo, for making this research possible. We are greatly indebted to Robert C. Dunnell, Donald K. Grayson, James B. Petersen, Donald L. Johnson, Jeff Homberg, Lee Nordt, and Rolfe Mandel for reading earlier drafts of this paper and providing extremely helpful comments. We remain responsible for any errors in reasoning. We also thank Armando M. Coimbra (in memoriam), Mario Borges, Katia Cassaro, Mara M. de Ângelo, Julie K. Stein, and Debora M. Kligmann for helpful ideas and support. The granulometric analysis was done by Elaine Sinfrônio at the LABSED of the Instituto de Geociências-USP. This experiment would not have been possible without the institutional support of the Fundação Jardim Zoológico de São Paulo and Departamento do Patrimônio Histórico da Prefeitura de São Paulo (DPH-SMC).

\section{REFERENCES}

Araujo, A.G.M. (1992). As propriedades físicas dos arenitos silicificados e suas implicações na aptidão ao lascamento. Revista do Museu de Arqueologia e Etnologia, São Paulo, 2, 63-74. 
Araujo, A.G.M. (1995). Peças que sobem, peças que descem e o fim de Pompéia: Algumas observações sobre a natureza flexível do registro arqueológico. Revista do Museu de Arqueologia e Etnologia, São Paulo, 5, 3-25.

Arts, N., \& Cziesla, E. (1990). Bibliographie (1880-1988) on the subject of refitting stone artefacts. In The Big Puzzle: International Symposium on Refitting Stone Artefacts (pp. 651-683), Studies in Modern Archaeology 1. Bonn: Holos-Verlag.

Baldus, H. (1937). Ensaios de etnologia brasileira. Rio de Janeiro: Campanhia Editora Nacional.

Balek, C.L. (2002). Buried artifacts in stable upland sites and the role of bioturbation: A review. Geoarchaeology, 17, 41-52.

Bocek, B. (1986). Rodent ecology and burrowing behavior: predicted effects on archaeological site formation. American Antiquity, 51, 589-603.

Bocek, B. (1992). The Jasper Ridge reexcavation experiment: Rates of artifact mixing by rodents. American Antiquity, 57, 261--269.

Bollong, C.H. (1994). Analysis of site stratigraphy and formation processes using patterns of sherd dispersion. Journal of Field Archaeology, 21, 15-28.

Bordes, F. (1972). Comptes Rendus- “La Grotte de l'Hortus.” Quaternaria, XVI, 299-305.

Cahen, D., \& Moeyersons, J. (1977). Sub-surface movements of stone artifacts and their implications for the prehistory of Central Africa. Nature, 266, 812-815.

Carter, T.S., \& Encarnação, C.D. (1983). Characteristics and use of burrows by four species of armadillos in Brazil. Journal of Mammalogy, 64, 103-108.

Dunell, R.C., \& Stein, J.K. (1989). Theoretical issues in the interpretation of microartifacts. Geoarchaeology, 4, 31-42.

Emmons, L.H., \& Feer, F. (1990). Neotropical rainforest mammals-A field guide. Chicago: The University of Chicago Press.

Erlandson, J.M. (1984). A case study in faunalturbation: delineating the effects of the burrowing pocket gopher. American Antiquity, 49, 785-790.

Folk, R.L. (1974). Petrology of sedimentary rocks. Austin, TX: Hemphill Publishing.

Golden Software, Inc. (1994). SURFER Version 5.01. Golden, Colorado.

Johnson, D.L. (1989). Subsurface stone lines, stone zones, artifact-manuport layers, and biomantles produced by bioturbation via pocket gophers (Thomomys bottae). American Antiquity, 54, 370-389.

Johnson, D.L. (1990). Biomantle evolution and the redistribution of earth materials and artifacts. Soil Science, 149, 84-102.

Johnson, D.L. (1993). Biomechanical processes and the Gaia Paradigm in a unified pedo-geomorphic and pedo-archaeologic framework: dynamic denudation. In J.E. Foss, M.E. Timpson \& M.W. Morris (Eds.), Proceedings of the First International Conference on Pedo-Archaeology (pp. 41-67), Special Publication 93-03. Knoxville, TN: University of Tennessee Agricultural Experimental Station.

Johnson, D.L. (2002). Darwin would be proud: Bioturbation, dynamic denudation, and the power of theory in science. Geoarchaeology, 17, 7-40.

Kintigh, K.W., \& Ammerman, A.J. (1982). Heuristic approaches to spatial analysis in archaeology. American Antiquity, 47, 31-63.

Kroll, E.M., \& Price, T.D. (1991). The interpretation of archaeological spatial patterning. Interdisciplinary Contributions to Archaeology. New York: Plenum Press.

Moeyersons, J. (1978). The behaviour of stones and stone implements, buried in consolidating and creeping Kalahari sands. Earth Surface Processes, 3, 115-128.

Pierce, C. (1992). Effects of pocket goffer burrowing on archaeological deposits: A simulation approach. Geoarchaeology, 7, 185-208.

Rolfsen, P. (1980). Disturbance of archaeological aayers by processes in the soil. Norwegian Archaeological Review, 13, 110-118.

Schiffer, M.B. (1987). Formation processes of the archaeological record. Albuquerque: University of New Mexico Press.

Siiriäinen, A. (1977). Pieces in vertical movement-a model for rockshelter archaeology. Proceedings of the Prehistoric Society, 43, 349-353. 


\section{ARAUJO AND MARCELINO}

Simek, J.F., \& Larick, R.R. (1983). The recognition of multiple spatial patterns: A case study from the French Upper Paleolithic. Journal of Archaeological Science, 10, 165-180.

Soil Survey Staff (1975). Soil taxonomy: A basic system of classification for making and interpreting soil surveys, Agriculture Handbook No. 436. Washington, DC: U.S. Department of Agriculture, Soil Conservation Service.

Stein, J.K. (1983). Earthworm activity: A source of potential disturbance of archaeological sediments. American Antiquity, 48, 277-289.

Taber, F.W. (1945). Contribution on the life history and ecology of the nine-banded armadillo. Journal of Mammalogy, 26, 211-226.

Talmage, R.V., \& Buchanan, G.D. (1954). The armadillo (Dasypus novemcinctus) - a review of its natural history, ecology, anatomy and reproductive physiology: The Rice Institute Pamphlet XLI. Houston, TX: The Rice Institute.

van Nest, J. (2002). The good earthworm: How natural processes preserve upland Archaic archaeological sites of Western Illinois, U.S.A. Goearchaeology, 17, 53-90.

Villa, P. (1982a). Conjoinable pieces and site formation processes. American Antiquity, 47, 276-290.

Villa, P. (1982b). Terra Amata and the Middle Pleistocene archaeological record of Southern France, University of California Publications in Anthropology No. 13. Berkeley, CA: University of California.

Villa, P., \& Courtin, J. (1983). The interpretation of stratified sites: A view from underground. Journal of Anthropological Science, 10, 67-281.

Wandsnider, L. (1996). Describing and comparing archaeological spatial structures. Journal of Archaeological Method and Theory, 3, 319-384.

Received September 15, 2001

Accepted for publication February 26, 2002 